\title{
Energy products from source-separated organic waste
}

\author{
G. K. Luk \& V. Bekmuradov \\ Department of Civil Engineering, Ryerson University, Canada
}

\begin{abstract}
An effective strategy adopted in recent years for municipal solid waste management is the source-separation of solid waste, most commonly into organics, recyclables such as glass, plastics and papers, and refuse. It has been proposed that source-separated organic waste (SSO) is an excellent lignocellulosic biomass of fermentable carbohydrates, and has the potential to serve as a low-cost feedstock for bioconversion into energy products such as ethanol and hydrogen. To evaluate the feasibility of converting SSO to energy products, a better understanding on the energy contents and highly-variable composition of SSO is needed. This paper is based on the results obtained from a ten-month analysis on the SSO collected from the City of Toronto, Ontario, Canada. Detailed analyses on the composition in terms of the VOC, cellulose, hemicellulose, and lignin contents, as well the amounts of carbohydrates, glucose, xylose and other fermentable sugars are carried out. The experimental results show that the average values of moisture content, at $55 \%$, and VOC, from $65 \%$ to $96 \%$ per dry mass, was sufficiently high to support microbial growth, making it an acceptable feedstock for anaerobic digestion. The results of SSO are compared to other traditional cellulosic feedstock, such as hardwood, agricultural products, food and herbaceous crops, and it was demonstrated that comparable amount of fermentable sugars are contained in SSO.

Keywords: source-separated-organic waste, ethanol, glucose, xylose.
\end{abstract}

\section{Introduction}

Waste generation is an unavoidable problem for many metropolitan cities around the world. The accumulation of waste results in numerous environmental, health and safety issues. The problem is getting worse and has been aggravated by the 
slow implementation of policy guidelines by solid waste management officials, at the national level, for materials recovery and recycling. An example is the waste disposal predicament of the City of Toronto, Canada, which has become critical pending the imminent closure of the city's major landfill site. In 2000, the City of Toronto established a goal of $100 \%$ waste diversion by the year 2010 and implemented a three-stream waste collection including recyclables, source-separated organics, and landfill waste [1]. The city of Toronto generates approximately 100,000 tonnes of source-separated organic waste (SSO) from single-family households per year. This provides a good opportunity for the source of feedstock to be converted into energy products. The SSO is an excellent lignocellulosic source of fermentable carbohydrates including free sugars, starches, and other degradable organic materials. Biomass, such as processed source-separated organic waste, is particularly attractive as it is widely available, often at a negative cost, together with many other environmental benefits. It may provide an alternative to fossil fuels and reduce greenhouse gas emissions, reduce farmland depletion from using crops for bioethanol production, and reduce the amount of generated waste.

Lignocellulose materials represent a large fraction of municipal solid waste. They consist of cellulose, hemicellulose, lignin, extractives, and several inorganic materials [2]. Cellulose is a crystalline biopolymer that is composed of glucose. Hemicellulose is also a carbohydrate, which comprises mainly of xylose, although traces of arabinose, mannose, and galactose can be found. Lignin is a complex and three-dimensional non-crystalline polymer composed of linked six-carbon phenolic rings with other carbon chains and chemical components. Lignin binds to the cellulose and hemicellulose fibers and protects them from hydrolysis of their monomeric sugars and fermentation into energy products $[3,4]$. At present, pre-treatment by physical, chemical, and biological means is necessary to enhance the biodegradability of lignocellulosic biomass in order to release the fermentable sugars and improve the yield of valuable energy products. An effective and economical pre-treatment must be chosen based on the composition of biomass and the desirable output.

This paper investigates the potential of using SSO as a lignocellulosic feedstock for bioethanol production. Since the nature of this highly-variable waste fluctuates widely over the year, and data on its contents is extremely sparse, a compositional analysis of SSO was performed over ten months with a large number of samples. The current study is focused on the development of a mass balance of the composition of SSO, for evaluating it as a usable feedstock for bioethanol production. A comparison to other more traditional lignocellulosic feedstock in terms of energy content, conversion efficiency, and sugars availability, is also carried out.

\section{Materials and methods}

The SSO waste samples used in this study were pre-processed mechanically under high temperature $\left(120^{\circ} \mathrm{C}\right)$ and pressure $(50$ bars $)$ by a thermal screw press (TSP) from the Vartek Waste Management Ltd., Toronto, Canada [5]. The 
heterogeneous SSO waste was pulverized and blended with a stabilizer, composed of $20-30 \%$ by weight of woodchips during pre-processing. As a result of the pre-processing, a stable, uniform, and almost odourless sample with an extended shelf life was obtained.

In order to minimize uncertainty in the analysis of SSO, a reliable sampling procedure was carried out, which included techniques of field sampling, laboratory sampling, homogenization, and chemical analyses (Jansen et al. [6]). Compositional analysis of the samples was performed according to the standard procedure by Hames et al. [7], which included oven drying, mixing, milling, and sieving. The portion remaining on ASTM sieve No. $80(>180 \mu \mathrm{m})$ was used for compositional analysis. The sample was spread on a tray and divided into a tenpart matrix, and sub-samples were then taken from each matrix for analysis of the parameters. Therefore, each parameter was measured ten times and the mean value of the data was reported. According to Jansen et al. [6], this method is most appropriate for highly variable samples, with an uncertainty between $3 \%$ and $10 \%$, and the results can be considered representative of the true characteristics of the pre-processed SSO. The experiment on the pre-processed SSO samples was repeated six times over a period of ten months, from September 2008 to June 2009. Statistical analyses were carried out to evaluate the integrity of the data, including the following: 1) sample range and tendency as represented by the maximum, minimum, median, and mean; 2) sample variation as represented by the standard deviation, standard error, $95 \%$ confidence intervals, sample variance, and Student T-test for analysis of variation from the mean.

The moisture content was obtained by drying the sample in a conventional oven at $105^{\circ} \mathrm{C}$ for 24 hours in order to achieve a constant weight. There is an unavoidable small error associated with this method, which is caused by the loss of some volatile solids in the heating, but the error is normally within $5 \%$. Volatile organic compounds (VOCs) of the pre-processed SSO samples were determined by the standard method [7], and includes ignition at $575^{\circ} \mathrm{C}$ for 15 minutes until a constant weight is achieved. Following ignition at $575^{\circ} \mathrm{C}$, only ash remains. The percentage of ash in the biomass samples was also an approximation of the mineral contents [7].

The caloric value of a sample represents the energy content, and was measured as the amount of energy that could be released in the form of heat during complete combustion of the samples. The caloric value of the SSO samples was determined at the AMEC Earth and Environmental Laboratory following method E870-82 of ASTM for "analysis of wood fuel" [8].

The extractives in the samples were determined by the ethanol extraction procedure from the Technical Association of Pulp and Paper Industry [9].

The carbohydrates present in the biomass samples were determined by chromatographic techniques. The procedure that was used to determine the carbohydrates in SSO was based on the NREL Laboratory Analytical Procedure (LAP) for the "determination of structural carbohydrate in biomass" [7]. The sample was analyzed by HPLC with Refractive Index (RI) detector and Aminex 
HPX-87P carbohydrate column. The results were corrected for the R (\%) factor, accounting for the loss of sugar during the hydrolysation by acids.

The analysis of lignin was based on the NREL Laboratory Analytical Procedure for "Determination of structural carbohydrates and lignin in biomass" [7]. The lignin content was measured as the loss in ignition at $575^{\circ} \mathrm{C}$ for four hours.

\section{Results and analyses}

\subsection{General analysis of characteristics}

The general characterization of the SSO samples included the determination of moisture content, total solids (TS), volatile organic compound (VOC), ash, and caloric value, and the results are summarized in Table 1. As indicated, each of these parameters was monitored for 6 samples collected over a duration of 10 months, and each measurement was repeated for 10 times to minimize the discrepancy.

Table 1: General characteristic of SSO samples.

\begin{tabular}{|c|c|c|c|c|c|c|}
\hline \multirow[t]{2}{*}{ Parameter } & \multicolumn{6}{|c|}{ SAMPLING PERIOD } \\
\hline & $09-2008$ & $11-2008$ & 03-2009 & 04-2009 & $05-2009$ & 06-2009 \\
\hline TS & $\begin{array}{c}48 \% \\
( \pm 1.5 \%)\end{array}$ & $\begin{array}{c}48 \% \\
( \pm 0.7 \%)\end{array}$ & $\begin{array}{c}39 \% \\
( \pm 1.8 \%)\end{array}$ & $\begin{array}{c}43 \% \\
( \pm 1.2 \%)\end{array}$ & $\begin{array}{c}44 \% \\
( \pm 1.0 \%)\end{array}$ & $\begin{array}{c}44 \% \\
( \pm 0.6 \%)\end{array}$ \\
\hline Moisture & $\begin{array}{c}52 \% \\
( \pm 1.5 \%)\end{array}$ & $\begin{array}{c}52 \% \\
( \pm 0.7 \%)\end{array}$ & $\begin{array}{c}61 \% \\
( \pm 1.8 \%) \\
\end{array}$ & $\begin{array}{c}57 \% \\
( \pm 1.2 \%) \\
\end{array}$ & $\begin{array}{c}56 \% \\
( \pm 1.0 \%) \\
\end{array}$ & $\begin{array}{c}56 \% \\
( \pm 0.6 \%)\end{array}$ \\
\hline $\begin{array}{l}\text { VOC per } \\
\text { dry mass }\end{array}$ & $\begin{array}{c}83 \% \\
( \pm 1.7 \%) \\
\end{array}$ & $\begin{array}{c}90 \% \\
( \pm 0.4 \%) \\
\end{array}$ & $\begin{array}{c}65 \% \\
( \pm 1.6 \%) \\
\end{array}$ & $\begin{array}{c}92 \% \\
( \pm 0.9 \%) \\
\end{array}$ & $\begin{array}{c}96 \% \\
( \pm 1.5 \%) \\
\end{array}$ & $\begin{array}{c}92 \% \\
( \pm 0.7 \%) \\
\end{array}$ \\
\hline $\begin{array}{l}\text { Ash per } \\
\text { dry mass }\end{array}$ & $\begin{array}{c}17 \% \\
( \pm 1.7 \%) \\
\end{array}$ & $\begin{array}{c}10 \% \\
( \pm 0.4 \%)\end{array}$ & $\begin{array}{c}35 \% \\
( \pm 1.6 \%) \\
\end{array}$ & $\begin{array}{c}8 \% \\
( \pm 0.9 \%) \\
\end{array}$ & $\begin{array}{c}4 \% \\
( \pm 1.5 \%) \\
\end{array}$ & $\begin{array}{c}8 \% \\
( \pm 0.7 \%) \\
\end{array}$ \\
\hline $\begin{array}{l}\text { TKN in } \\
\mu \mathrm{g} / \mathrm{g}\end{array}$ & 13,200 & 4,300 & 12,500 & 8,650 & 10,300 & 6,240 \\
\hline $\begin{array}{l}\text { Caloric } \\
\text { Value in } \\
\mathrm{kJ} / \mathrm{kg}\end{array}$ & -- & -- & 13,232 & -- & 20691 & -- \\
\hline
\end{tabular}

As shown in Table 1, the average moisture content of the samples was quite high, from $52 \%$ to $61 \%$, even though some moisture loss had occurred during the pre-treatment with the ATS machine. This high amount of moisture in the SSO samples indicates an improved potential for biodegradability, as water is essential for all microbial growth. The amount of VOC in the SSO samples is also sufficiently high, from $65 \%$ to $96 \%$ per dry mass, making it an excellent feedstock for anaerobic digestion. 


\subsection{Carbohydrate content}

In the process of ethanol production through fractionation and bacterial fermentation of biomass, the dominant sources of carbon for microbial growth are carbohydrates. Cellulose, hemicellulose, and starch are the most significant components as they can be converted to ethanol or other energy products. Starch is a carbohydrate that is mainly composed of glucose. Previous studies (Guffey and Wingerson [10]) have confirmed that over 90\% of cellulose is composed of glucose and over $90 \%$ of hemicellulose is composed of xylose. Therefore, by measuring the total amount of glucose and xylose, a rough estimation of the amount of total fermentable carbohydrates in the SSO sample can be obtained. Table 2 is a summary of the results for quantitative saccharification of the SSO samples.

Table 2: Fermentable carbohydrate contents of the SSO samples.

\begin{tabular}{|c|c|c|c|c|c|c|}
\hline \multirow[t]{2}{*}{ Parameter } & \multicolumn{6}{|c|}{ SAMPLING PERIOD } \\
\hline & 09-2008 & $11-2008$ & 03-2009 & 04-2009 & 05-2009 & 06-2009 \\
\hline Glucose & $\begin{array}{c}25.8 \% \\
( \pm 2.0 \%)\end{array}$ & $\begin{array}{c}38.2 \% \\
( \pm 2.0 \%)\end{array}$ & $\begin{array}{c}30.6 \% \\
( \pm 0.7 \%)\end{array}$ & $\begin{array}{c}27.3 \% \\
( \pm 2.6 \%)\end{array}$ & $\begin{array}{c}34.8 \% \\
( \pm 3.6 \%)\end{array}$ & $\begin{array}{c}27.1 \% \\
( \pm 2.0 \%)\end{array}$ \\
\hline Xylose & $\begin{array}{c}19.8 \% \\
( \pm 2.0 \%)\end{array}$ & $\begin{array}{c}10.5 \% \\
( \pm 0.9 \%)\end{array}$ & $\begin{array}{c}22.0 \% \\
( \pm 0.1 \%)\end{array}$ & $\begin{array}{c}17.3 \% \\
( \pm 2.0 \%)\end{array}$ & $\begin{array}{c}27.8 \% \\
( \pm 3.0 \%)\end{array}$ & $\begin{array}{c}17.5 \% \\
( \pm 2.0 \%)\end{array}$ \\
\hline Arabinose & $<3 \%$ & $<3 \%$ & $<3 \%$ & $<3 \%$ & $<3 \%$ & $<3 \%$ \\
\hline Mannose & $<3 \%$ & $\begin{array}{c}8.0 \% \\
( \pm 0.8 \%) \\
\end{array}$ & $\begin{array}{c}3.0 \% \\
( \pm 0.3 \%) \\
\end{array}$ & $\begin{array}{c}9.6 \% \\
( \pm 1.5 \%) \\
\end{array}$ & $\begin{array}{c}4.5 \% \\
( \pm 1.0 \%) \\
\end{array}$ & $\begin{array}{c}3.6 \% \\
( \pm 0.9 \%) \\
\end{array}$ \\
\hline Galactose & $<3 \%$ & $<3 \%$ & $<3 \%$ & $<3 \%$ & $<3 \%$ & $<3 \%$ \\
\hline Total Sugars & $45.6 \%$ & $56.7 \%$ & $55.6 \%$ & $54.2 \%$ & $67.1 \%$ & $48.3 \%$ \\
\hline
\end{tabular}

Each value in Table 2 is the mean of a set of replications for each month of analysis, and its error margin was calculated with $95 \%$ confidence. As shown in Table 2, glucose is prevalent, ranging from 26 to $38 \%$, reflecting a considerable contribution of starch and cellulosic compounds in the composition of SSO. The data also demonstrates the presence of xylose up to about $28 \%$, which indicates a considerable amount of hemicellulose in the SSO samples. The amount of glucose that was quantified by HPLC could be from cellulose, starch, or free sugars in the samples, but the amount of xylose is mainly from hemicellulose. The results show that the amount of total fermentable glucose and xylose is satisfactory for SSO to be considered as an energy production feedstock.

\subsection{Acid insoluble lignin}

The percentage of lignin was measured over the ten-month study period, with ten sets of replications for each sample, and the results are summarized in Table 3. 
Table 3: Acid-insoluble lignin contents of the SSO samples.

\begin{tabular}{ccccccc}
\hline Sample & \multicolumn{5}{c}{ SAMPLING PERIOD } \\
\cline { 2 - 7 } & $09-2008$ & $11-2008$ & $03-2009$ & $04-2009$ & $05-2009$ & $06-2009$ \\
\hline $\mathbf{1}$ & $26.03 \%$ & $22.12 \%$ & $18.51 \%$ & $29.62 \%$ & $18.51 \%$ & $22.02 \%$ \\
\hline $\mathbf{2}$ & $26.87 \%$ & $22.90 \%$ & $18.51 \%$ & $30.03 \%$ & $22.22 \%$ & $22.12 \%$ \\
\hline $\mathbf{3}$ & $26.70 \%$ & $20.98 \%$ & $22.22 \%$ & $29.62 \%$ & $22.22 \%$ & $22.01 \%$ \\
\hline $\mathbf{4}$ & $25.70 \%$ & $19.76 \%$ & $18.51 \%$ & $30.33 \%$ & $25.92 \%$ & $22.65 \%$ \\
\hline $\mathbf{5}$ & $20.65 \%$ & $21.01 \%$ & $18.51 \%$ & $29.62 \%$ & $22.22 \%$ & $22.10 \%$ \\
\hline $\mathbf{6}$ & $24.30 \%$ & $17.87 \%$ & $18.99 \%$ & $29.62 \%$ & $18.51 \%$ & $21.90 \%$ \\
\hline $\mathbf{7}$ & $34.20 \%$ & $19.76 \%$ & $16.12 \%$ & $28.01 \%$ & $18.70 \%$ & $20.56 \%$ \\
\hline $\mathbf{8}$ & $21.20 \%$ & $24.02 \%$ & $21.01 \%$ & $31.01 \%$ & $22.32 \%$ & $22.03 \%$ \\
\hline $\mathbf{9}$ & $27.01 \%$ & $21.80 \%$ & $19.01 \%$ & $29.89 \%$ & $21.38 \%$ & $22.10 \%$ \\
\hline $\mathbf{1 0}$ & $25.90 \%$ & $24.96 \%$ & $18.19 \%$ & $30.09 \%$ & $22.12 \%$ & $22.54 \%$ \\
\hline Mean & $25.86 \%$ & $21.51 \%$ & $18.96 \%$ & $29.78 \%$ & $21.41 \%$ & $22.00 \%$ \\
\hline S. Dev. & $3.7 \%$ & $2.1 \%$ & $1.6 \%$ & $0.7 \%$ & $2.3 \%$ & $0.5 \%$ \\
\hline $\mathbf{9 5} \% \mathbf{C I}$ & $\pm 2.6 \%$ & $\pm 1.5 \%$ & $\pm 1.1 \%$ & $\pm 0.5 \%$ & $\pm 1.6 \%$ & $\pm 0.4 \%$ \\
\hline
\end{tabular}

The results indicate a consistent presence of lignin in the SSO samples during the period of this study, which is unfavourable to the process of biological degradation. Therefore, for a successful biological conversion of the SSO to ethanol, particular attention must be devoted to the design of an effective de-lignification pre-treatment of the feedstock, in order to facilitate the process of degradation and microbial fermentation to produce valuable energy products.

\subsection{Extractives}

The amount of extractives was determined for the SSO samples during the period of study. Table 4 shows the percentage of extractives per dry weight of SSO samples.

Table 4: Extractives in the SSO samples.

\begin{tabular}{lcccccc}
\hline Parameter & \multicolumn{7}{c}{ SAMPLING PERIOD } \\
\cline { 2 - 7 } & $09-2008$ & $11-2008$ & $03-2009$ & $04-2009$ & $05-2009$ & $06-2009$ \\
\hline Extractives & $7.50 \%$ & $6.80 \%$ & $7.60 \%$ & $7.40 \%$ & $4.40 \%$ & $10.40 \%$ \\
& $( \pm 0.5 \%)$ & $( \pm 0.4 \%)$ & $( \pm 0.5 \%)$ & $( \pm 0.6 \%)$ & $( \pm 0.3 \%)$ & $( \pm 1.1 \%)$ \\
\hline
\end{tabular}

As shown in Table 4, the amount of extractives varies a lot over the ten months of analysis, which could be due to the heterogeneous nature of SSO. The amount of extractives varies due to several factors, such as the plastic content of the samples, fat, grease, paint, and other materials that are all common components in SSO. 


\subsection{Mass balance}

Mass balance for the SSO samples was constructed based on the average values of the sampling obtained during the 10-month period time. Due to their correlation with the ability to be fermented, the main parameters of interest are glucose, xylose, lignin and extractives. The remaining materials are protein, fat, synthetic materials, or any other unknown substances. Figure 1 shows the time-averaged mass balance diagram for the dry weight of the SSO samples.

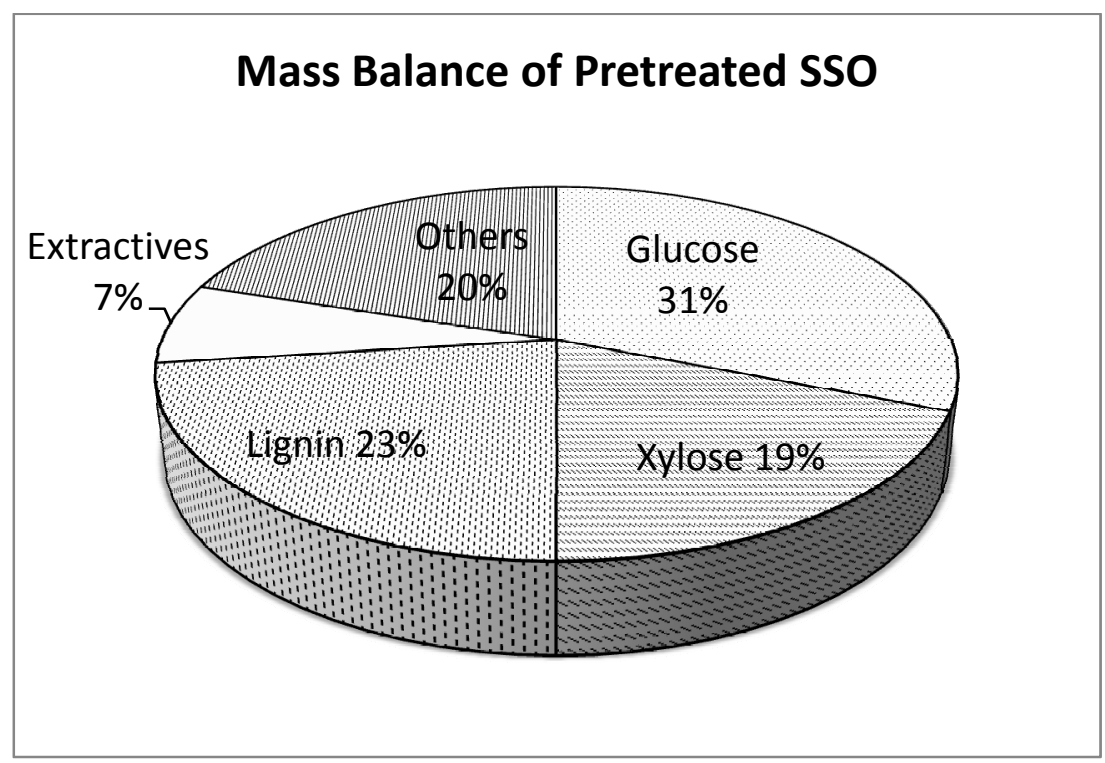

Figure 1: Mass balance of the SSO samples.

As illustrated in Figure 1, the percentages of glucose and xylose in the SSO samples, totalling to approximately $50 \%$, is satisfactory with a low level of variation from the mean value. Therefore, it may be concluded that SSO could be considered as a valuable feedstock for energy production. However, it should be noted that the blend of $20 \%$ wood waste in the SSO samples plays a significant role in increasing the carbohydrate content and reducing the month-to-month fluctuations in the results, due to the amount of glucose and xylose found in wood. Most literature has suggested that SSO should not be used nor tested on its own due to its volatile nature. This is consistent with the conclusions reached by Claassen et al. [11], who recommended that the organic fraction of municipal solid waste (OFMSW) is not an ideal substrate for energy products formation if it is utilized alone, but when used as a co-substrate with another cellulosic feedstock, satisfactory performance has been observed. A blend of construction wood chips was added to the organic waste in this study because the combination of the organic waste with construction and demolition wood waste not only enhances the potential ability of the feedstock to be 
fermented by increasing the amount of carbohydrate, but it also decreases the month-to-month fluctuations of the SSO, in the analysis of characteristics. Moreover, the addition of wood chips in the SSO provides a number of other benefits such as increasing the shelf life of the feedstock and increasing its stability.

\subsection{Theoretical ethanol yield}

According to Wyman [12], it may be assumed that glucose has a 95\% conversion and xylose has an $85 \%$ conversion to ethanol under optimal conditions. Therefore, based on the mean values for glucose and xylose from the mass balance diagram in Figure 1, each tonne of dried SSO can be converted to approximately 265 litres of ethanol, for which 171 litres is from glucose fermentation and 94 litres is from xylose fermentation. In 2006, the City of Toronto in Ontario collects approximately 100,000 tonnes of SSO per year from 460,000 single-family households [13]. According to the results for compositional analysis, approximately $45 \%$ of this is the dry weight, which means that 45,000 tonnes of dried SSO is collected per year from the City of Toronto. Based on the above premise, approximately 12,000,000 litres of ethanol can theoretically be produced annually from SSO. The actual amount of ethanol production would be less than the theoretical yield, owing to some limitations in conversion and fermentation efficiencies.

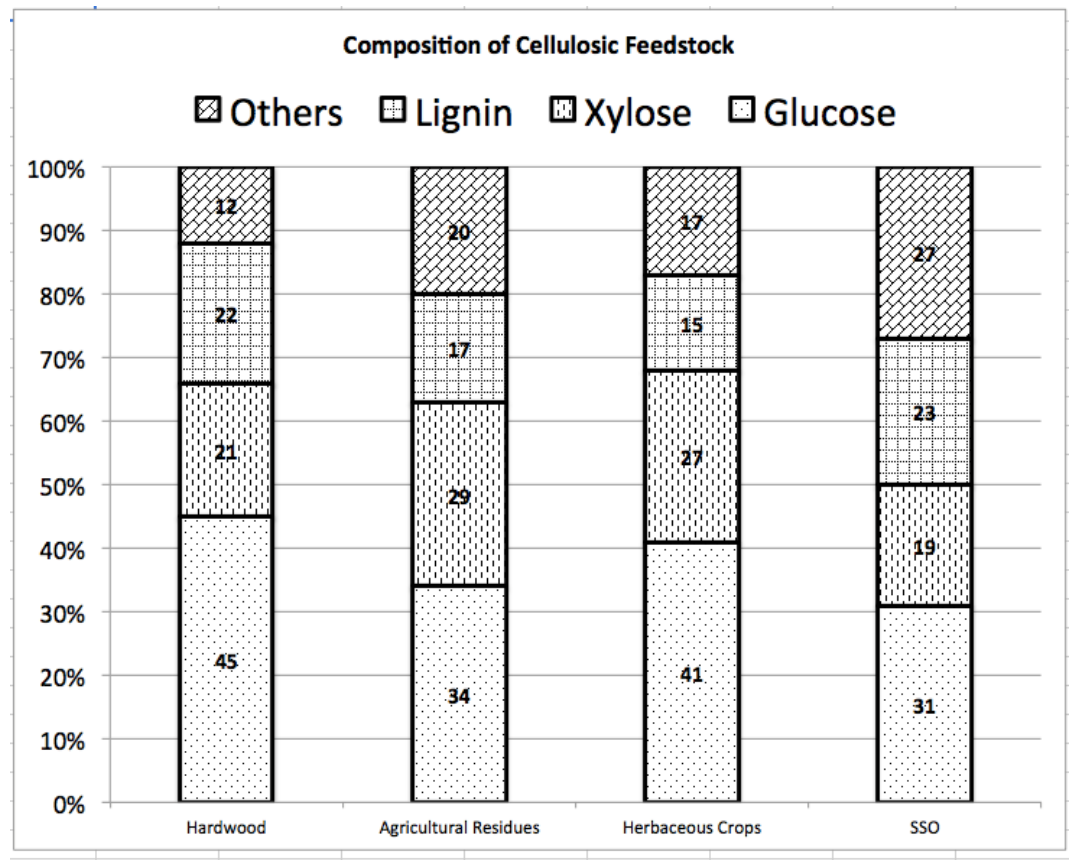

Figure 2: Comparison of SSO composition with other cellulosic feedstock. 
Figure 2 shows the comparison of the SSO composition with other traditional feedstock reported by Aden et al. [14]. It may be observed that the total amount of carbohydrates in SSO for energy product formation, as represented by the sum of glucose and xylose, is quite comparable to those from other cellulosic substrates. Therefore, SSO makes a highly competitive feedstock when compared to other types of traditional feedstock, but SSO is even more attractive in comparison owing to its low (or even negative) cost and other environmental benefits.

\section{Conclusions}

The experimental results show that the average values of moisture content and VOC of SSO were sufficiently high to support microbial growth, making it an acceptable feedstock for anaerobic decomposition for energy products formation. In terms of fermentable sugars availability, the results from the ten-month study of SSO averages to around 51\%, a value which is only slightly smaller than that of other traditional cellulosic feedstock, such as hardwood, agricultural products, food and herbaceous crops. The SSO waste samples utilized in this study were pre-processed by the thermal screw press (TSP) for further characterization and evaluation for low-cost energy source. It was found that the pre-processed SSO in this study contains high sugars and carbohydrate content, with good conversion efficiency, all of which are essential for energy production. Based on these findings, greater emphasis should be placed on the value of utilizing SSO as a feedstock instead of using dedicated energy crops. In conclusion, the finding of this study will enhance the overall understanding of the nature of SSO and provides the much-needed technical data to solid waste managers, when analysing the cost-benefits of source-separation of waste, as well as to evaluate the potential of using SSO for conversion to energy products.

\section{Acknowledgements}

The authors are extremely grateful to the technical support of the Department of Civil Engineering, and also to the staff of graduate studies of Ryerson University for the facilities and assistance provided throughout this research. Special thanks are given to the supplier of the pre-processed SSO samples, Vartek Waste Management Ltd., Toronto, Canada.

\section{References}

[1] City of Toronto. Solid Waste Management Services. Briefing Notes. Status of Residential Waste Diversion. 2004. http://www.toronto.ca/ budget2004/pdf/wesswmstatusoreswastdiv_edited.pdf

[2] Taherzadeh, M. and Karimi, K. Pre-treatment of cellulosic waste to improve ethanol and biogas production: A review. International Journal of Molecular Science, 9, pp. 1621-1651, 2008. 
[3] Lynd, L. R. Overview and evaluation of fuel ethanol from cellulosic biomass: Technology, economics, the environment, and policy. Annual Review of Energy and the Environment, 21, pp. 403-65, 1996.

[4] Wyman, C. E. Handbook on Bioethanol: Production and Utilization. pp. 180-190 and pp. 395-410.Washington, DC: Taylor and Francis, 1996.

[5] Vartek Waste Management Ltd. Vartek ATS Technology Compost Pilot Test. Toronto, Ontario, Canada, 2005.

[6] Jansen, J. L. C., Spliid H., Hansen, T. L., Savard, A., Christensen, T. H. Assessment of sampling and chemical analysis of source-separated organic household waste. Waste Management, 24(6), pp. 541-549, 2004.

[7] Hames, B., Ruiz, R., Scarlata, C., Sluiter, A., Sluiter, J. and Templeton, D. Preparation of Samples for Compositional Analysis Laboratory Analytical Procedure (LAP). Technical Report, NREL/TP-510-42620, 2008.

[8] ASTM Standard Test Methods for Analysis of Wood Fuels, ASTM E870-82, 2013.

[9] Technical Association of the Pulp and Paper Industry (TAPPI). T264 om88. "Preparation of wood for chemical analysis". In Tappi Test Methods. Atlanta, GA., 1988.

[10] Guffey, F. D., Wingerson, R. C. Fractionation of lignocellulosic biomass for fuel-grade ethanol production. Department of Energy's (DOE) Office of Scientific and Technical Information (OSTI). SciTech Connect 2002. http://www.osti.gov/bridge/servlets/purl/807155kbdGYV/native/807155.p df

[11] Claassen, P. A. M., Budde, A. M. W., and Lopez-Contreras, A. M. Acetone, Butanol and Ethanol production from domestic organic waste by solventogenic clostridia. Journal Molecular Biotechnology, 2(1), pp. 3944, 2000.

[12] Wyman, C.E. "Ethanol from lignocellulosic biomass- technologies, economics, and opportunities". Bioresource Technology, 50(1), pp. 3-16, 1994.

[13] City of Toronto. Green Bin Newsletter. March/April 2006. $\mathrm{http}: / /$ www1.toronto.ca/wps/portal/contentonly?vgnextoid=ceed $433112 \mathrm{~b} 0$ 2410VgnVCM10000071d60f89RCRD

[14] Aden, A., Ruth, M., Ibsen, K., Jechura, J., Neeves, K., Sheehan, J., and Wallace, B. Lignocellulosic biomass to ethanol process design and economics utilizing co-current dilute acid prehydrolysis and enzymatic hydrolysis for corn stover. NREL/TP-510-32438, 2002. 